\title{
Pseudotumoral Colic Tuberculosis: A Rare Pathological Entity
}

\section{Eddy Oleko Ekuke ${ }^{*}$, Pierlesky Elion Ossibi1, El Mahdi Benkoukous1, Moussa Sylla1, Boubacar Efared2, Laila Chbani'², Abdelmalek Ousadden1, Khalid Mazaz1, Khalid Ait Taleb1}

${ }^{1}$ Visceral Surgery Department, Hassan II University Hospital, Fez, Morocco

${ }^{2}$ Anatomy and Pathological Cytology Department, Hassan II University Hospital, Fez, Morocco

Email: ^Olekoekuke20121982@gmail.com

How to cite this paper: Ekuke, E.O., Ossibi, P.E., Benkoukous, E.M., Sylla, M., Efared, B., Chbani, L., Ousadden, A., Mazaz, K. and Taleb, K.A. (2016) Pseudotumoral Colic Tuberculosis: A Rare Pathological Entity. Surgical Science, 7, 522-527.

http://dx.doi.org/10.4236/ss.2016.712069

Received: August 2, 2016

Accepted: December 18, 2016

Published: December 21, 2016

Copyright $\odot 2016$ by authors and Scientific Research Publishing Inc. This work is licensed under the Creative Commons Attribution International License (CC BY 4.0). http://creativecommons.org/licenses/by/4.0 (c) (i) Open Access

\begin{abstract}
Colic tuberculosis is rare even in countries endemic to Mycobacterium spp. Its incidence seems to be increasing over the last decade. Presentation in the form of abdominal mass is exceptional and often misdiagnosed as gastrointestinal tumor. The possibility of a colic involvement of this infection needs to be considered given the broad spectrum of clinical manifestations of TB infection. We present a case of pseudo colic tuberculosis in a 58-year-old patient with no history of disease.
\end{abstract}

\section{Keywords}

Colon, Tuberculosis, Pseudo-Tumor

\section{Introduction}

Tuberculosis is a contagious microbial disease caused by Mycobacterium tuberculosis. The abdominal affection is as old as the history of mankind, relatively common and represents $5 \%$ to $10 \%$ of all localisations [1]. It is fourth in line after the pulmonary, lymph node, bone and joint localisations. It affects the peritoneum, gastrointestinal tract, abdominal lymph nodes, liver, spleen and pancreas. The most common abdominal localisations are: ileocecal, peritoneal and lymph node. Colonic localisations remain rare. We report a case of pseudotumoral colic tuberculosis in a 58-year-old patient with no significant history discovered on right hemicolectomy specimen.

\section{Case Report}

Patient, 58-year-old female without significant clinical history, presented with an 
isolated right upper and lower quadrants pain with gradual weight loss dating back 4 months prior to her admission.

Physical examination found a conscious patient, stable vitals with no abdominal tenderness or palpable mass.

Abdominal ultrasound: a hypo-echoic mass of the right flank measuring 7 $\mathrm{cm} \times 4 \mathrm{~cm}$ with a hyper echoic inner ring resembling a digestive wall thickening (Figure 1).

Colonoscopy: presence of a circumferential impassable stenosing lesion at the right colic flexure of which multiple biopsies were performed.

Pathological examination of the biopsies came back for a sub acute nonspecific colitis with no malignant lesions.

Thoracic Abdomino pelvic CT revealed a gastrointestinal wall thickening at the right colic flexure, $22 \mathrm{~mm}$ thick and $66 \mathrm{~mm}$ long associated with an infiltration of surrounding fat and numerous lymphadenopathy with the largest measuring $16.5 \mathrm{~mm}$ (Figure 2 and Figure 3).

The case was discussed at a multidisciplinary oncology meeting where surgery was indicated.

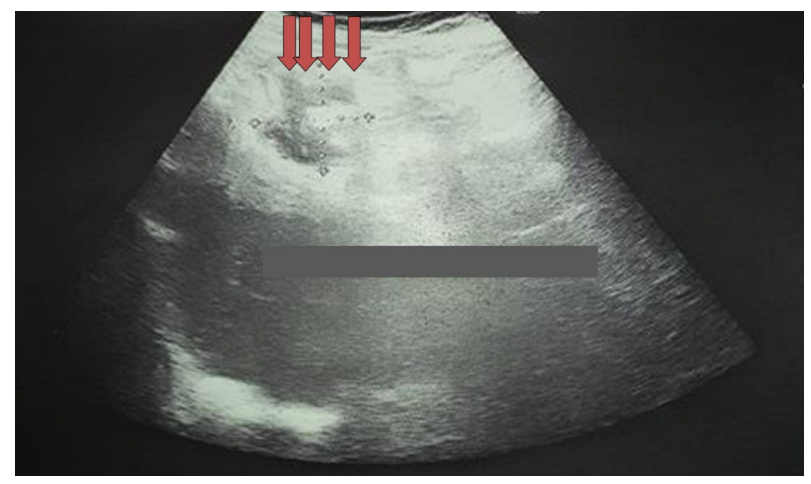

Figure 1. Abdominal ultrasound showing hypo echoic mass of the right lumbar region surrounded by a slightly hper echoic ring.

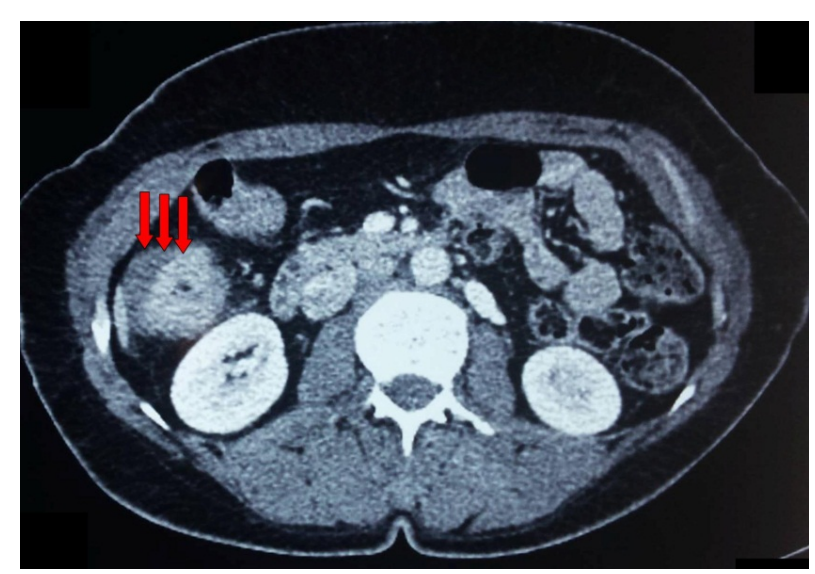

Figure 2. Abdominal CT axial section showing tissue thickening of the digestive wall at the right colic flexure. 
A large tumor of the right colic flexure was discovered per operatively and right hemicolectomy was done with subsequent ileocolonic anastomosis

Pathology examination of surgical specimen returned for a caseo-follicular tuberculosis of the colon (Figure 4).

The patient was placed under anti TB treatment with favorable outcome and no recurrence till date.

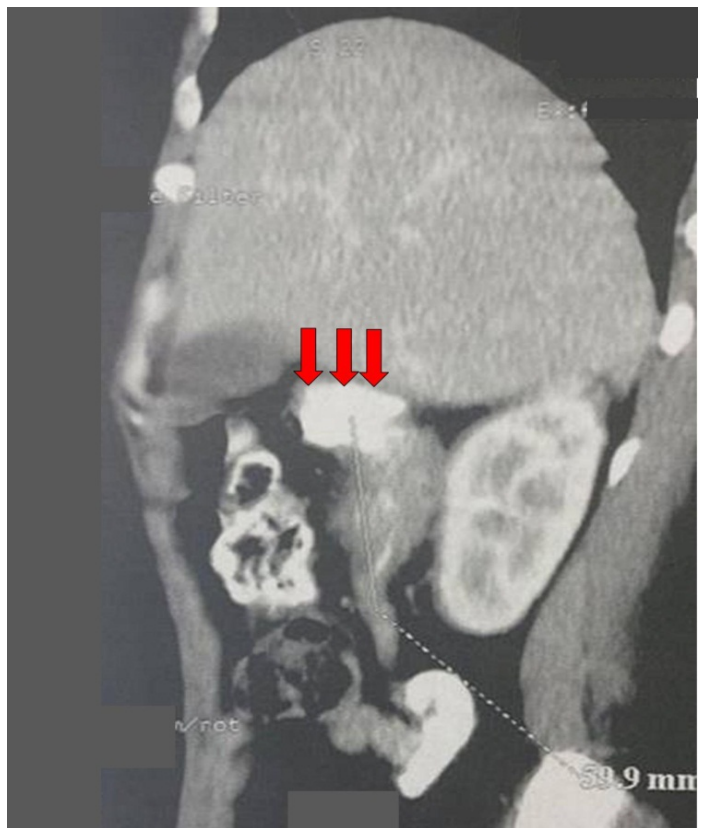

Figure 3. Abdominal CT scan sagittal reconstruction revealing a tissue thickening of the digestive wall at the right colic flexure.

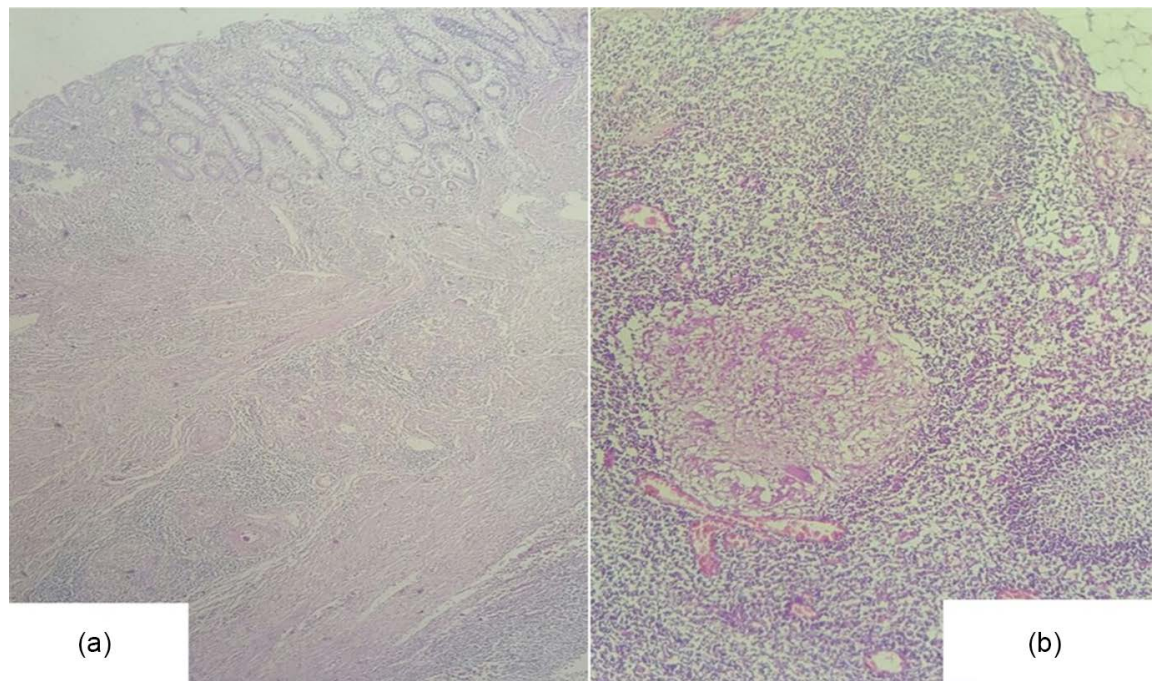

Figure 4. (a) Image showing destruction of colic wall by numerous granulomas made up of giant and epithelioid cells with caseous necrosis (HES $\times 100$ ); (b) Image showing lymph node granulomas consisting of epithelioid and giant cells with surrounding caseous necrosis $($ HES $\times 200)$. 


\section{Discussion}

The incidence of TB infection has experienced a re-ascension not only in emerging countries but also in developed countries. This is explained in part by the surge in incidence of human immunodeficiency virus (HIV) infection, malnutrition and immigration [2]. Thus resulting in an increase in incidence of extra-pulmonary localisations which account for almost $1 / 3$ of all TB cases reported in Morocco [1]. Abdominal localisation represents a relatively common extra pulmonary localisation, accounting for $5 \%$ to $10 \%$ of all TB infections [1]. The incidence could be higher and may even double to triple the figures reported in HIV-positive patients. It is estimated to be about $13.5 \%$ in a recent study collating 199 HIV seropositive cases [1]. In abdominal tuberculosis all organs may be affected, and the most common sites of involvement include the small intestine (44\%), the cecum (35\%) and ileocecal junction (16\%) [1]. Isolated involvement of the colon is rare; it is estimated to be around $2 \%$ and $9 \%$ with predominance of right colic involvement [1] as was the case in our patient.

Gastrointestinal involvement may be primitive by direct ingestion of mycobacterium or secondary to haematogenous or lymphatic spread of lung lesions [3]. The bacterial causative agent is usually Mycobacterium tuberculosis, bovine or human, or rarely atypical mycobacterium in immunocompromised patients [3]. Hypertrophic pseudotumoral forms are most often primitive [1] affecting young adults between 20 and 40 years [4]. A slight female predominance is observed in most cases of intestinal involvement [5].

However it is still difficult to assess the incidence of pseudotumoral forms of abdominal tuberculosis [2] with only $5 \%$ of cases reported in literature [1].

Symptoms of gastro intestinal tuberculosis are variable and differ widely from that of peritoneal tuberculosis which often presents as abdominal pain usually accompanied with ascites as tell tale symptoms [6].

The clinical presentation of gastrointestinal tuberculosis is generally non specific, resulting in weight loss, low grade fever, painful abdominal bloating, constipation, ascites, and diarrhea sometimes with dysentery, when there is rectosigmoid involvement or pertains to a pseudotumoral form [1].

Most feared complications include bowel perforation, usually compartmentalized, bowel obstruction, hemorrhage or malabsorption in the case of ileocecal involvement [1].

On other hand, observed anomalies on lab tests like anemia or inflammatory syndrome are non specific. A positive tuberculin skin test (TST) is no confirmation of adjacent abdominal TB infection. A plain chest $\mathrm{x}$-ray may help confirm or otherwise the secondary nature of the affection [1].

Thanks to ultrasound and CT, imaging represents a decisive step in the diagnosis of pseudotumoral forms [1].

Intestinal involvement prevails at the ileocecal junction as agglomerated loops with thickened walls usually concentric [1]. Concentric wall thickening can be 
heterogeneous with hypo dense zones representing areas of caseous necrosis [1]. The diagnosis of ileocecal tuberculosis remains difficult as ileocecal involvement can easily mimic Crohn's disease, certain neoplasm or appendicular tumor [1].

More so, TB can affect any segment of the digestive tract. It often presents as clustered bowel loops, a digestive wall thickening with peritoneal nodules, or an amalgamation of deep lymph nodes including mesenteric lymphadenopathy. However this aspect may not always be present, and in the presence of a hypertrophic digestive wall infiltration with accompanying peritoneal nodules, a gastro intestinal tumor is often suspected [1].

Surgical management is not clearly defined and depends essentially on the indication of surgery. Thus, the existence of one or more zones of obstruction in case of bowel obstruction or emergent surgery in the event of massive bleeding tends to make bowel resection imperative. It also largely depends on the nature of lesions and the extent of damage discovered per operatively and involves mostly bowel resections with or without anastomosis or by pass or even ostomy. The type of resection undertaken must always take into account the part of GI tract that requires resection.

If it were too large, especially at the ileum, ostomy should be preferred first counting on TB treatment to reduce the extent of secondary resection that would be needed [1].Secondly, intra operative findings do not always suggest the tubercular nature of pseudotumoral forms and diagnosis can only be made after histological examination of the surgical specimen [1]. Thus surgery must always be associated with TB treatment as was the case in our patient. Postoperative complications do not differ from that observed in other indications. However, the relatively higher incidence of postoperative mortality could be explained by the fact that TB patients often consult late after long periods of evolution and with deteriorated general condition [1].

\section{Conclusion}

Pseudotumoral colic tuberculosis is a rare disease entity even in endemic countries. It poses a problem of differential diagnosis especially gastrointestinal malignancy thus often justifying the need for surgical exploration whenever reasonable doubt exists or in the event of complications.

\section{References}

[1] El Barni, R., Lahkim, M. and Achour, A. (2012) Abdominal Pseudotumoral Tuberculosis. Pan African Medical, 13, 32.

[2] Denis-Delpierre, N., Merrien, D., Billaud, E., Besnier, J.M., Duhamel, E., et al. (1998) Extrapulmonary Tuberculosis in the Central Western Region. Retrospective Study of 217 Cases (Gerico 1991-1993). Presse Medicale, 27, 341-346.

[3] De Jesus, L.E., Marques, A.M., Rocha, M.S., et al. (2004) Left Colon Stenosis Caused by Tuberculosis. Journal of Pediatric Surgery, 39, e5-e7.

https://doi.org/10.1016/j.jpedsurg.2004.06.041 
[4] Ibrarallah, M., Mohan, A., Sakari, A., Srinivas, M. and Mishra, A. (2002) Abdominal Tuberculosis: Diagnosis by Laparoscopy and Colonoscopy. Tropical Gastroenterology, 23, 150-153.

[5] Marshall, J.B. (1993) Tuberculosis of the Gastrointestinal Tract and Peritoneum. The American Journal of Gastroenterology, 88, 989-999.

[6] Tanrikulu, A.C., Aldemir, M., Gurkan, F., Suner, A., Dagli, C.E. and Ece, A. (2005) Clinical Review of Tuberculous Pritonitis in 39 Patients in Diyarbakir. Journal of Gastroenterology and Hepatology, 20, 906-909.

\section{Scientific Research Publishing}

Submit or recommend next manuscript to SCIRP and we will provide best service for you:

Accepting pre-submission inquiries through Email, Facebook, LinkedIn, Twitter, etc.

A wide selection of journals (inclusive of 9 subjects, more than 200 journals)

Providing 24-hour high-quality service

User-friendly online submission system

Fair and swift peer-review system

Efficient typesetting and proofreading procedure

Display of the result of downloads and visits, as well as the number of cited articles

Maximum dissemination of your research work

Submit your manuscript at: http://papersubmission.scirp.org/

Or contact ss@scirp.org 